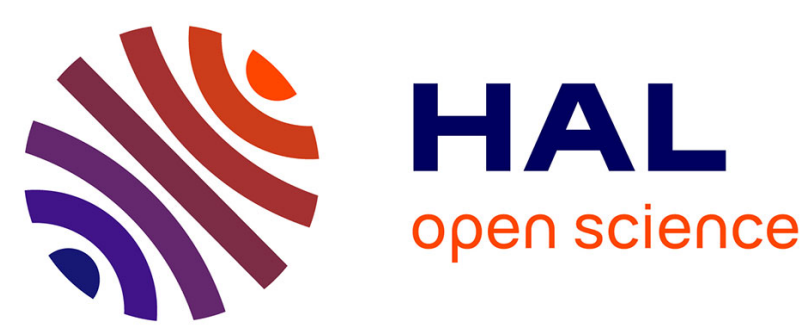

\title{
Epistemological Intelligence
}

\author{
Steven James Bartlett
}

\section{To cite this version:}

Steven James Bartlett. Epistemological Intelligence. 2017. hal-01429159

\section{HAL Id: hal-01429159 \\ https://hal.science/hal-01429159}

Preprint submitted on 7 Jan 2017

HAL is a multi-disciplinary open access archive for the deposit and dissemination of scientific research documents, whether they are published or not. The documents may come from teaching and research institutions in France or abroad, or from public or private research centers.
L'archive ouverte pluridisciplinaire HAL, est destinée au dépôt et à la diffusion de documents scientifiques de niveau recherche, publiés ou non, émanant des établissements d'enseignement et de recherche français ou étrangers, des laboratoires publics ou privés.

\section{(a)(1) $\$$}

Distributed under a Creative Commons Attribution - NonCommercial - NoDerivatives $\mid 4.0$ 


\section{EPISTEMOLOGICAL INTELLIGENCE}

by

STEVEN JAMES BARTLETT 


\section{An open access publication}

Due to word-count limits of most professional journals, the author has chosen to issue this monograph as a free open access publication under the terms of the Creative Commons Attribution-NonCommercial-NoDerivs license, which allows anyone to distribute this work without changes to its content, provided that both the author and the original URL from which this work was obtained are mentioned, that the contents of this work are not used for commercial purposes or profit, and that this work will not be used without the author's or his executor's permission in derivative works (i.e., you may not alter, transform, or build upon this work without such permission). The full legal statement of this license may be found at

http://creativecommons.org/licenses/by-nc-nd/4.0/legalcode

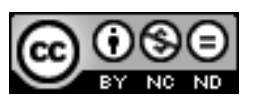




\title{
EPISTEMOLOGICAL INTELLIGENCE
}

\section{STEVEN JAMES BARTLETT}

\begin{abstract}
This monograph continues a discussion begun in three earlier papers by the author which described the psychology of philosophers. Here, the author identifies a set of important skills that are essential to what he has called epistemological intelligence; these skills are examined in relation to a group of psychological characteristics shared by many philosophers and by many students attracted to the study of philosophy. The monograph's twofold purpose is to recognize epistemological intelligence as a distinguishable variety of human intelligence, one that is especially important to philosophers, and to understand the challenges posed by the psychological profile of philosophers that can impede the development and cultivation of the skills associated with epistemological intelligence.
\end{abstract}

Keywords: epistemological intelligence, psychology of philosophers, psychology of individual differences 


\section{EPISTEMOLOGICAL INTELLIGENCE}

\section{CONTENTS}

\1. Two approaches to the study of epistemology ...................... 1

\2. A set of epistemological skills.....................................................

\$3. From a defined set of skills to the recognition of a new variety of intelligence..................................................................

\4. Is epistemological intelligence no more than a theoretical construct?................................................................

§5. The psychology of philosophers ............................................13

\$6. The personality structure of philosophers as seen through the lens of confirmation bias .....................................18

\$7. Non-philosophical studies of so-called "epistemological understanding".

\8. Epistemological intelligence and individual differences

§9. Can epistemological intelligence be taught? Can it be learned?

Appendix: The Projection of Transcendence

References

About the author. 


\title{
EPISTEMOLOGICAL INTELLIGENCE ${ }^{1}$
}

\author{
STEVEN JAMES BARTLETT
}

\section{\$1. Two approaches to the study of epistemology}

There is, on the one hand, a form of human thinking that is essentially epistemological. On the other hand, there is the subject of study, epistemology, the product of epistemological thought. The former is not epistemology, but is a precondition for epistemology's successful realization. The latter is that realization, sometimes successful, sometimes not. The two belong to very different species. It is the first, epistemological thinking and the skills that make it possible, that will concern us here.

The most common definition of epistemology is "the study of the limits and conditions of knowledge." There are two very distinct ways of studying such "limits" and "conditions." In most universities, epistemology is taught as a content-based subject-matter: In this approach, individual epistemological theories that have been formulated by historically famous philosophers are described and

\footnotetext{
${ }^{1}$ In 2005, I published a book, The Pathology of Man: A Study of Human Evil, which sought to provide a comprehensive understanding of why people behave aggressively, destructively, and often maliciously, and in the process cause great suffering to others, and often to themselves as well. The conclusion I reached was that these very human dispositions result from a wide variety of factors, among them what I have called "moral intelligence" (cf. also Bartlett, 2002). Deficits in moral intelligence combine with other factors to bring about the destructive human thought processes and behavior that I wished to explain.

Toward the end of The Pathology of Man, I introduced another concept, "epistemological intelligence," to refer to a set of special abilities which, from my years as a student and then as a university professor, I have seen are possessed by comparatively few people. I have written this monograph because the subject of epistemological intelligence deserves its own independent discussion.
} 
critiqued. Relatively seldom is epistemology taught as a skill-based discipline_as, literally, a reflective mental discipline, understood in terms of a specific set of well-defined skills, whose purpose is to enable the identification and clarification, within the individual mind of each student, of just what those "limits and conditions of knowledge" actually are.

If the objective of a class in epistemology were to focus on the particular cognitive skills that are epistemologically useful, the individual student will ideally learn to distinguish and to separate, without undue self-conscious effort, his or her own mere beliefs, on the one hand, from states of solid and reliable knowledge, on the other. But not only this, and again ideally, the student will come to recognize the need to revise his or her fundamental ways of understanding and conceptualizing the world, by means of a two-step process that discards unanalyzed, previously accepted, baseless beliefs, and then replaces them with a set of reflectively analyzed and justifiable claims.

This approach to epistemology is not only less familiar to most professional philosophers, for many it is unknown. The notion that there is a specific set of epistemologically valuable "well-defined skills" is likely to be questioned, and by some philosophers also opposed. A skill-based approach to epistemology in the sense just described itself comprises a philosophical position that for some stands in need of philosophical justification.

Recognizing the legitimacy of a skeptical response like this, I need to make my modest intentions in this monograph clear. There are two relevant and important issues: On the one hand, we may wish to have an adequate philosophical justification for specifying the particular skills that I will identify. This is a justification that the teacher of the specified skills must be able to provide. On the other hand, we may also be interested in the degree to which philosophy students and professional philosophers may encounter difficulties in developing and applying those skills. 
My objectives here are focused and therefore limited: As is common in mathematics, I propose to ignore the first issue by reducing it to a problem previously solved: that is, to refer readers to certain of my previous publications if they wish to know the philosophical justification for the approach that is in view. ${ }^{2}$ Here, my interest is instead in the second issue: variability in the epistemological abilities of individual students and of professors of philosophy, a subject that will lead us to examine the nature of epistemological intelligence.

In much of my university teaching and in many of my publications, I have focused on epistemology in this skill-based sense. In the process, it has become clear to me that comparatively few people are able to develop the relevant skills in a proficient and lasting way.

This was initially a depressing realization-certainly an instance in which facts fail to satisfy what one would prefer. But once the fact of individual cognitive differences made itself evident in a skill-based epistemological context, it was then only a small step to ask, Why is this the case? and What does this reveal about the workings of the individual philosophizing mind?

\section{\$2. A set of epistemological skills}

The following are among the main reflective thinking skills I have sought to communicate to students and to readers of my published work; some of these skills qualify, in my view, as epistemologically "special" because they are largely unique to epistemological study and are relatively unknown and unused outside of epistemology. In the list below, I am not concerned to provide an exhaustive enumeration of all relevant skills, nor to establish the independence of each skill from the others:

\footnotetext{
2 See Bartlett (1970, 1975, 1976, 1982, 1983a, 1983b, 2005, 2011, 2015, 2016).
} 
(1) a commitment to logical coherence and alertness to inconsistency

(2) a commitment and a sensitivity to identify beliefs that are baseless, that is, have no empirical or logical justification

(3) a commitment and a will to eliminate, to the extent that this is possible, baseless beliefs from one's own thinking

(4) a commitment to seek revisionary replacements, again to the extent that this is conceptually possible, for beliefs recognized as baseless, and a determination to accomplish this

(5) an ability to recognize that all claims to knowledge are inextricably framework-relative, that is, cannot be asserted when disassociated from the conceptual framework(s) that must be accepted in order for it to be possible to make those claims

(6) a heightened awareness of the ways in which some scientific and many commonly accepted and widely used concepts trespass beyond the frameworks they presuppose, and by doing this, become self-destructively incoherent

(7) a "mental dynamic" of a certain sort, one that has been developed within the individual's mind, perhaps through training or perhaps simply because the person's mind finds this natural, to invest credence only in rationally justifiable ways of understanding and rationally justifiable claims that can be made on this basis

(8) the establishment of what I have elsewhere ${ }^{3}$ called a "rational bridge," which connects, on the one hand, the preceding reflectively, self-consciously justified and formulated understanding and claims with, on the other hand, both the individual's own predispositions to think and behave in certain ways, and actual cognitive and behavioral conduct consistent with those predispositions

${ }^{3}$ Bartlett (1969-70, 2016). 
These Basic Eight skills are evidently of different kinds: (1)-(4) and (8) each explicitly combines distinct psychological and cognitive commitments with specific skills. (1) combines a certain variety of commitment with an individual's alertness to inconsistency. Alertness can be considered a species of ability or of skill, which, like all skills, is susceptible to variation among individual people. (2) also combines a certain focus of commitment with a form of sensitivity to baseless beliefs, again a variable human ability. (3) combines a type of commitment with a degree of volition to eliminate baseless beliefs from one's thinking, and degree of volition, of will power, may also be considered an ability, a kind of skill. (4), too, bonds commitment with an individual's degree of determination to find revisionary replacements. (5) refers explicitly to a specific ability, the ability to recognize framework-relativity, again a skill that varies among individuals. (6) refers to a beightened awareness of instances of framework trespassing, also a skill-based proficiency. (7), as well, points to an individual's ability to establish within his or her mind a conceptual habit or pattern of thinking that leads the person to believe only when there is a justifiable basis for such belief. (8) is, I have observed, less of a "skill" than a description of the consequence, at least for some individuals, of the acquisition, solidification, and strengthening of the preceding seven skills.

Some of these skills, abilities, or proficiencies are clearly more "specialized" in terms of their application within epistemology than are the others. Many people, especially scientists, develop skills of the first three kinds: They are committed to logical coherence, and are alert to inconsistencies in their thought and research results; they have learned to develop a sensitivity to empirically baseless or mathematically unfounded claims; and they are committed to eliminating baseless beliefs and claims that are made as a result of them.

The fourth skill tends to be found in more creative individuals, and less among conventional thinkers and researchers who do not 
push the boundaries in attempts to initiate revisionary or revolutionary approaches.

The fifth skill, that of recognizing the framework-relativity of claims, is today, I suggest, found primarily among physicists whose work focuses on relativity and quantum theory; in both of these areas of study, framework-relativity is not only recognized, but is firmly embedded in the very fabric of special and general relativity and of quantum mechanics. ${ }^{4}$ But in its most general, theoretically abstract form, the skill of recognizing the framework-relativity of knowledge claims is essentially an epistemological skill.

The sixth skill—a heightened awareness of ways in which we tend to trespass beyond the boundaries of the frameworks we presuppose-is a skill I have tried explicitly to communicate and to encourage others to make part of their thinking. It is a skill that, in my experience in teaching and publishing, is difficult to impart and to encourage in individuals, for reasons I shall get to shortly.

The seventh skill—-to limit one's credence to the justifiable-is a commonly advocated skill, whether among professional philosophers, or skeptics, or scientists and mathematicians. But when this skill is tied to the previous ability of recognizing frameworkrelativity, it is not often cultivated by many people; indeed, I have found, by very few.

The eighth and last skill—really the establishment of a direct and reliable connection between an individual's rational skills and understanding, and his or her cognitive and behavioral conduct-is also, again in my observation, rather rarely found among people. ${ }^{5}$

The set of eight skills that I've identified, when they are combined together by a single mind, some of them common to professionals in

${ }^{4}$ Cf. Bartlett (1980; 2016, p. 10).

5 On the surface, this appears to express a mere subjective opinion. It does not. There is a strong evidence that supports it. See Bartlett (2011, "The Distribution of Mental Health, pp. 273-276), which charts the distribution of both positive and negative mental health. The higher, positive end of the spectrum includes those comparatively rare individuals in whom a rational bridge has formed that links their rationality with consistent behavior in the sense intended in the text. 
various fields, and some more epistemologically centered, constitute what I shall call a minimal set of epistemological abilities.

\section{\$3. From a defined set of skills to the recognition of a new variety of intelligence}

Investigators of human intelligence have taken as fundamental the close association of specific abilities or skills with corresponding distinct varieties of intelligence. To give a few historical examples: In 1895, Alfred Binet and Victor Henri were critical of then-existing intelligence tests due to the tests' tendency to oversimplify; Binet and Henri sought to persuade other intelligence researchers to develop a diversity of tests to measure distinguishable human mental abilities, including, for example, tests of imagination, attentiveness, memory, richness of mental imagery, verbal and mechanical comprehension, aesthetic appreciation, and even the capacity to sustain muscular effort and moral sensibility. (Binet and Henri, 1895) They proposed ways of testing these various categories of traits, as they called them. They considered all of these to comprise varieties of human ability or capability, or, what I shall often call them here, skills.

Later, E. L. Thorndike (1920) added to the classification of forms of intelligence when he proposed a special kind of "social intelligence"; he considered it distinct from traditionally measured intellectual intelligence, and identified it as "the ability to understand and manage people” (p. 275). Some decades later, social psychologists Bruner and Tagiuri (1954) directed attention to three distinguishable abilities involved in the perception of others: the ability to recognize the emotions that others feel based on their expressions, the ability to judge personality traits on the basis of the external behavior of others, and the ability to form impressions and formulate judgments of others. During the next decade, J. P. Guilford (1967) proposed a "multidimensional conception of intelligence" (p. 467), in which he classified some 120 distinguishable abilities. 
More recently, Solovey and Mayer (1990), Gardner (1993/1983; 1989), and Goleman (1995) have proposed the recognition of "emotional intelligence," which recognizes the existence of a set of skills that enables one to become aware of one's own emotions and those of others. Still more recently, in my studies of the psychology of animal rights (Bartlett, 2002) and of human pathology (Bartlett, 2005), I proposed the need to recognize "moral intelligence," defined in terms of a set of four specific, basic abilities that enable an individual to avoid succumbing to psychologically normal predispositions to violence, aggression, and destructiveness.

These historical examples drawn from slightly more than a century's research concerning human intelligence provide a useful background framework. We can see that, as psychologists have become increasingly aware of distinguishable sets of human abilities, they have often associated those sets of abilities with corresponding varieties of intelligence. There are certain values in doing this, for it can help us to understand more clearly and explicitly different classes of human abilities; it makes it possible to focus investigation on identifiable discrete abilities; it may help us to learn how to develop and cultivate humanly important varieties of skills; and it enables us to understand how individual people vary in their capacities to learn and improve those skills.

In keeping with this gradually solidifying paradigm that links distinct ability sets with distinguishable forms of intelligence, toward the end of my book, The Pathology of Man (Bartlett, 2005, p. 304), I coined the term 'epistemological intelligence' to refer to a set of special abilities, abilities that are involved in the study and development of epistemology when it is understood as a skill-based discipline. Like all abilities that are correlated with separately recognizable forms of intelligence, those underlying epistemological intelligence are-as I have already suggested-highly variable among individuals. In fact, as we shall see, there are convincing reasons why the skills involved in epistemological intelligence are subject to so much individual variability. 


\section{\$4. Is epistemological intelligence no more than a theoretical construct?}

Definitions come in several kinds; the most familiar varieties include lexical definitions (as found in a dictionary), stipulative definitions, and real definitions. ${ }^{6}$ When we question whether a definition—such as the definition of "epistemological intelligence" presented here-is a mere theoretical construct, at the root of the question is a concern whether what is being defined may be nothing more than a semiarbitrary assemblage of defining factors (the "skills" I have associated with the term "epistemological intelligence"), which are gathered together and stipulatively asserted to constitute a distinguishable set that is noteworthy in some respect.

If we pause for a moment to consider this question and the concern it expresses, we find that, at its root, is a presumption that some definitions are, as it were, "privileged" in that they are thought to provide truthful information about the real world. Definitions of this kind have been given the name "real definitions," which were described long ago by Aristotle as statements that express the essence of a thing-important facts about that thing, facts from which other truths can be obtained. Einstein's definition of 'simultaneity' is often thought to be of this kind. Unlike stipulative definitions, real definitions are thought to inform one about reality, and not simply to express a meaning that is to be agreed upon on the basis of mere convention. Real definitions purport to provide us with trustworthy information about real things by being descriptive of empirical reality, and therefore those that do this successfully are considered to comprise true statements.

Elsewhere, I have examined a closely related subject, the so-called species problem in biology. ${ }^{7}$ This is a famous problem for biologists, and specifically for taxonomists. For centuries, there has been

\footnotetext{
${ }^{6}$ For a detailed discussion of varieties of definition and an analysis of their principal uses and misuses, see Bartlett (2011, Chapter 2).

${ }^{7}$ Bartlett (2015).
} 
controversy over whether taxonomic divisions of classification are "discovered" or "imposed" upon the multiplicity of living things, whether they refer to "real divisions," or are fundamentally arbitrary.

We come face-to-face with the same issue in connection with any definition of a form of intelligence: Does that definition, one might ask, really discriminate reality along naturally existing lines of demarcation?, or Does that definition merely stipulate, perhaps on someone's self-asserted authority, that it should be accepted as a convention, and possess no more compelling force than this? Let us call this the "definition problem" in parallel with the "species problem" of biology.

Without unreasonably broadening my focus here, I do not propose to develop a full answer to these questions, and, besides, interested readers can find that answer given elsewhere. ${ }^{8}$ For my purposes here, a short summary of the conclusions reached may be sufficient, translating those conclusions so as to apply to our present discussion:

Those conclusions are, essentially, these two: First, whatever efforts we make to answer the question whether "epistemological intelligence" constitutes a real definition of a "distinctly real variety of human intelligence" —or, instead, "merely a stipulated theoretical construct"- - those efforts must fail because such a question does not recognize the theoretical impossibility of what it seeks: There is an inescapable ambiguity that necessarily affects any identification that clusters together a set of defining elements, as I will explain in a moment. And, second, any such clustering of defining elements presupposes a framework in terms of which those elements may be identified, and, by virtue of this inescapable fact, that particular identified clustering of elements cannot not be accepted without inconsistency: The very identification of the elements comprising the cluster is, in my terminology, "self-validating."

${ }^{8}$ See the previous note. 
To explain these claims as briefly as possible here: ${ }^{9}$ When we consider any set of elements and recognize that a subset of them shares a certain property, the very possibility of this recognition relies upon the application, sometimes explicit or conscious, and sometimes not, of a criterion of commonality. It is only relative to such a criterion that a subset of elements can be recognized as sharing the property or properties specified by the criterion. The "inescapable ambiguity" mentioned in the previous paragraph results from the logical fact that even elements that we perceive to be different share the same number of properties as do elements that we perceive to share the same properties. Theoretical physicist and mathematician Satosi Watanabe was one of the first people to recognize and to prove this "logical fact," which he called "the theorem of the ugly duckling." ${ }^{10}$ In his words, the theorem "claims that an ugly duckling and a swan are just as 'similar' to each other as are two swans." Watanabe (1965, p. 39). Here lies the justification for the first claim relating to the inescapable ambiguity involved in any identified clustering of elements that we may recognize.

Once a criterion of commonality has been established, relative to which we recognize that, from a set of elements, a certain subset satisfies that criterion, there is no possible contention that can arise without inconsistency. - Notice that the preceding sentence begins with the establishment of a "ground rule," so to speak: Given a certain criterion of commonality, and given that we do recognize that a certain group of elements satisfies that criterion, on this established basis then to reject the recognized cluster that we have identified through the application of the specified criterion would be inconsistent. It is inconsistent in a particular way, one that attempts to "pull the carpet out from beneath our feet"- - to deny, in other words, the very preconditions that must be met in order to identify the specified cluster.

\footnotetext{
${ }^{9}$ An explanation and justification for these claims will be found in Bartlett (2015).

10 A detailed account of his theorem is given in Bartlett (2015). See especially Watanabe (1965); then Watanabe (1969, 1985, 1986).
} 
In a series of publications, I have studied ways in which a wide variety of concepts, and hence a wide variety of claims that we make employing them, entail a denial of the preconditions that must be granted in order for those concepts and claims to be capable of referring and to be meaningful. I have called such self-undermining concepts and claims "projections" to express the sense in which their users are negligent of, or wish or intend to go beyond-and, in the process, to trespass - the inherent limitations of the requisite frameworks of reference. Such a self-undermining concept or claim is termed "projective" or a "projective misconstruction," and the method by means of which such concepts are eliminated I have called "deprojection."11

The conclusion that follows from this reasoning is that we would be engaged in a theoretically futile search if we insist upon deciding between the two alternatives, whether epistemological intelligence is a real definition or a theoretical construct. Epistemological intelligence, as defined here, is a recognizable clustering of certain skills, and once identified as it has been defined, its value as a recognized set of abilities is wholly a matter of choice. This applies equally to all defined varieties of intelligence, whether the skills they cluster together are evidenced through IQ tests, memory tests, dexterity tests, moral reasoning tests, emotional or aesthetic sensitivity tests, etc. Each and every identified variety of intelligence is a matter of choice, which is a function of the importance placed on the relevant underlying skills. In the case of epistemological intelligence, that choice depends upon the usefulness to us in recognizing a certain cluster of skills important and fundamental in epistemological thinking. The concept of epistemological intelligence can be useful if one's interest in epistemology includes the development and improvement of the set of eight skills previously described; otherwise, it probably is not.

\footnotetext{
11 For an abbreviated justification, see Bartlett (2015); for a more comprehensive account, see Bartlett (1970, 1976, 1982, 1983a, 1983b). For an example of a widespread projection, see the Appendix to this monograph.
} 


\section{\$5. The psychology of philosophers}

In the first section of this monograph, I raised two questions: Both suggest that when the eight skills I have associated with epistemological intelligence are made an area of study and cultivation, a large amount of individual variability makes itself evident: Some students of philosophy, as well as some professional philosophers, exhibit these skills in a strongly evident way, while others do not. The two questions I raised were: Why is this the case? and What does this reveal about the workings of the individual philosophizing mind? If one is interested in psychological dimensions of philosophizing and in the psychology of professional philosophers, these two questions can be illuminating.

With training and research in clinical psychology, I became interested in this general area of study, the psychology of philosophy and of philosophers, and published a group of papers in the 1980s dealing with this topic. ${ }^{12}$ Since then, as far as I've been able to determine, philosophers have not added to this research about their own psychology, very likely because few have backgrounds also in clinical psychology. In the meantime, psychology and its recent offshoot, so-called "behavioral economics," have, nonetheless, made some relevant observations about a similar underlying psychology possessed by any group of people who defend vested interests. Given philosophy's fundamental credo that an unexamined life-even one that remains unexamined from a psychological perspective-is undesirable, in what follows I shall try to summarize some of these main psychological results that apply specifically to the philosophical enterprise and to the individual psychology of many philosophers and of many students attracted to philosophical study. By doing this, we shall be able to throw some light on the specific skills I have

${ }^{12}$ Bartlett (1986a, 1986b, 1989). 
clustered under the heading of epistemological intelligence, and explain the wide variability of those skills among individuals.

I start with an abbreviated summary of some of the main psychological observations made in the three published papers cited in the previous footnote.

In Bartlett (1986a), I directed attention to several forms of defensiveness exhibited by many philosophers:

i. Controversy between philosophers ensues when their systems of belief come into conflict. For many, their preferred systems of belief are rooted in their sense of self and of professional identity, and therefore philosophical disagreement can easily be experienced as personally threatening. Challenges to that set of beliefs can be intimidating and often result in a defensive response.

ii. When a system of beliefs stakes out one's sense of identity, that system of beliefs tends to close the mind to competing, alternative, or conflicting ideas. In this sense, a philosophical system of beliefs becomes an ideology, allegiance to which comes to have the character of a solipsistic creed, hermetically closing off that system of beliefs from potential challenge.

iii. The close wedding of personal and professional identity to a self-enclosed, hermetically sealed system of ideas results in an inevitable filtering effect, one that sifts incoming, as well as outgoing, would-be communications with other minds. This filter imposes restrictive limits on what one is willing to see, admit, or question.

iv. Philosophical positions and ideologies generally-like their propounders-are exceptionally resistant to external criticism; they possess an "almost inconceivable hardihood" (Passmore, 1961, p. 63), a conceptual and psychological imperviousness in the face of opposition. 
v. A philosopher's sense of self, reflected in his or her system of intellectual and psychological commitments, is frequently expressed in an intention to formulate an all-inclusive theory of reality, and hence to claim that it "includes all relevant evidence." This is a frame of reference that is, essentially, exclusionary.

vi. As a result, philosophical positions, and the philosophers who espouse them, tend to become monadically isolated from one another, preventing genuine communication.

vii. As long as (i)-(vi) remain dominant in the psychology of philosophers, explicit controversy between competing views, true dialogue between conflicting ideologies, cannot succeed.

In Bartlett (1986b), I summarized the principal set of defining characteristics of clinical narcissism. The following caveat was expressed early in that paper:

Philosophers, like other people, are subject to human frailties. Some are probably clinical narcissists. I do not know if a larger proportion of philosophers is narcissistic than are theologians, poets, composers, artists, or writers. But probably, for reasons I will try to make clear, a greater proportion of the philosophical population suffers from characteristics of unacknowledged narcissism than do, for example, scientists.... [T] he nature of philosophic activity promotes and is encouraged by many qualities of personality which closely resemble qualities that define narcissism. (pp. 21-22)

The value in recognizing aspects of clinical narcissism in the psychological constitution of many philosophers is not to derogate, but rather to understand the challenges that result in a profession which-like all professions, as the interest inventories of psychometrists show-possesses among many of its practitioners a 
distinctive, recognizable, and characteristic set of psychological propensities. As described in Bartlett (1986b), certain of the defining characteristics of clinical narcissism apply to the philosophical personality:

viii. During its long history, philosophy and its practitioners have generally resisted the development of a unitary, evaluative framework. In contrast, science is the enemy of intellectual narcissism: It does not sanction the privilege of privately formed judgment, but requires the consensus, based on evidence, of the scientific community. Occasionally, individual philosophers have urged that philosophy become scientific, which is equivalent to advocating that the private willfulness of individual systems-building submit itself to an agreed-upon unitary methodology. ${ }^{13}$ As we have seen in (i)(vi) above, there are compelling psychologically-based forces that stand in the way of such a development.

ix. The psychology of philosophers is characterized by contentiousness: It is the life-blood of position-taking and resulting philosophical interaction. Its goal is to show that one is right, and that the other is wrong. As a result, philosophical argumentation combines self-demonstration with attempts to show that the opposition is mistaken.

x. Philosophical position-taking is essentially defensive, seeking to evade criticism. Often this is attempted through the cultivation of vagueness and terminological obscurity, a "smoke-screen in which only initiates can navigate confidently" (Bartlett, 1986b, p. 25). I have called this propensity "intellectual deviousness."

13 As Husserl once commented, "philosophers meet but, unfortunately, not the philosophies. The philosophies lack the unity of a mental space in which they might exist for and act on one another" (Husserl, 1965, p. 5). 
xi. The psychological underpinning of the practice of a discipline that defines itself through position-taking consists in the development of resistance to external pressures to force change in positions taken. This internal resistance, itself a kind of "intellectual lassitude" that develops within the mind of the position-taking philosopher and is then incarnated in the position espoused, is one of the defining features of clinical narcissism. It serves to mask fear that one's efforts are tenuous or flawed.

In Bartlett (1989), I sought to bring together certain of the preceding psychological observations within a context that recognizes that all disciplines - some to a greater, and some to a lesser extentattract and encourage practitioners who have distinguishable personality structures. In connection with mathematics, for example, an obsessive-compulsive personality structure can sometimes confer a significant benefit upon creative work. Outer-, socially-oriented individuals are attracted to sales, teaching, or social work, and can become competent professionals in these fields. There is sometimes a positive role that a professional's personality structure contributes to his or her growth, and also to that of the person's discipline. But sometimes the characteristic personality structure possessed by practitioners of a discipline can interfere with and obstruct its positive growth.

The characteristics and propensities listed above, (i-xi), may, whether all or only a subset of them, be combined within a single philosophical personality. When this happens, the person's sense of self and professional identity lead him or her to embrace positions that come to function as ideologies; the filtering effect that results encourages conceptual and psychological imperviousness to outside criticism, an imperviousness that is fundamentally exclusionary, monadically isolated, and resistant to the development of a broader, embracing, unitary evaluative framework. The mindset to which these 
propensities lead is one of contentiousness, defensiveness, and resistance to pressures that would force a change of view.

After nearly three decades of continued psychologically-focused observations of my fellow philosophers and of students who are drawn to philosophy, the conclusion I reached in the late 1980s remains one that I've found no evidence to revise:

When these qualities [i.e., (i-xi)] dominate a field of thought, they are surely maladaptive. The discipline cannot advance. It chases its tail. The clutch slips, and though the engine races, the vehicle that philosophical reflection affords remains stationary. It will continue to make promises, but remain incapacitated, unable to fulfill them.... If the psychological observations offered here are on the right track, then it follows that it will be difficult, even a priori impossible, to find anything that is capable of conveying an effective message to the majority of philosophers across the boundaries of their island universes of meaning. To be enmeshed in an ideology of one's own fashioning is incompatible with the awareness that one's commitments are ideological. (Bartlett, 1989, pp. 304305)

\section{\$6. The personality structure of philosophers as seen through the lens of confirmation bias}

Confirmation bias, as the term is typically used in the psychological literature, connotes the seeking or interpreting of evidence in ways that are partial to existing beliefs, expectations, or a bypothesis in hand.... If one were to attempt to identify a single problematic aspect of buman reasoning that deserves attention above all others, the confirmation bias would have to be among the candidates for consideration. Many have written about this bias, and it appears to be sufficiently strong and pervasive that one is led to wonder whether the bias, by itself, might account for a significant fraction of the disputes, altercations, and 
misunderstandings that occur among individuals, groups, and nations.

- Raymond S. Nickerson (1998, p. 175)

In Bartlett (1989), I commented: "To my knowledge, no experimental psychological study has ever been made of philosophers as a group" (p. 297). In the years since then, as far as I've been able to determine, it is still the case that no such experimental psychological study has been undertaken. However, two areas of research have developed whose findings are indirectly applicable to the focus here on what I take to be the dominant personality structure of philosophers. I shall look at certain of the relevant results of one of these areas of study in this section, and consider the second area of research in the following section.

In the past few decades, psychologists and behavioral economists have become interested in investigating the human phenomenon of confirmation bias. So much has now been written about it that confirmation bias has received the pet name "myside bias." There are many studies, both experimental and theoretical, that could be mentioned here and applied to the personality structure of philosophers and of students who gravitate to the profession. However, my assessment is that only rather little that has been written and experimentally evidenced having to do with confirmation bias adds appreciably to the philosophically-focused observations already described in $\$ 5$. But sometimes a slight change of perspective can bring with it a stronger understanding of a subject-matter; to that end, I summarize a few of the conclusions that psychologists and behavioral economists have come to affirm that are pertinent to the previously described psychological propensities of philosophical defensiveness (i-vi) and of characteristics of philosophical narcissism (viii-xi). By doing this, we may gain a more complete understanding of some of the major blocks that stand in the way of many individuals who might wish to develop and improve the specific epistemological skills (1-8) identified in $\$ 2$. 
One of the most widely accepted conclusions about confirmation bias that has now earned near-universal consensus among myside researchers is this: Once a person has taken a position, the immediate psychological sequelae are to find ways to justify it. To give an example that closely parallels the position-taking of philosophers, consider taxonomists: ${ }^{14} \mathrm{~A}$ taxonomist's focal interest is to formulate a system of classification that purports - whether in biology, botany, atomic physics, materials science, etc.- to express the real structure, the authentic, empirically based divisions and distinctions, of the domain of objects of concern to the taxonomist. Having constructed such a taxonomy, the natural, and hard-to-resist, psychological consequence for the taxonomist is the strong tendency then to perceive his or her subject-matter in terms of the specified system of classification. This effect upon the conceptual-perception faculties of the taxonomist is an almost direct embodiment of the Sapir-Whorf linguistic relativity hypothesis, for readers acquainted with that thesis.

And so, the first consequence of the creation of a taxonomic system of classification is to channel the taxonomist's own thinking and observations so as to conform to the designated categories. But, closely following on this is a second important consequence, that of leading the taxonomist actively to search for substantiating evidence that supports the now-preferred system of classification, and, unfortunately, also to avoid considering evidence that conflicts with or undermines that system. Both selective, cherry-picking-searching and exclusion of contrary evidence are instances of confirmation bias.

The two psychological sequelae in this taxonomy-creation example-channeled, filtered thinking and biased evidence selection-which have repeatedly been observed in studies of confirmation bias, are recognized to involve both a motivational component as well as a component reflecting cognitive limitations, ${ }^{15}$ some of which are discipline-specific, and some quite general. It is

\footnotetext{
14 See, e.g., Nickerson (1998, pp. 183-184).

15 For example, Kunda (1990) and numerous publications that have followed her paper.
} 
admittedly often difficult to disentangle which component is a stronger contributor to confirmation bias; some researchers lean more one way, some the other. But in the context of our present concern with the dominant personality structure of philosophers, this difficulty is significantly reduced because it is reasonably straightforward to separate the motivational component from the cognitive skills component when we consider the two previous lists: the list of the eight identified epistemological skills and their associated motivational factors, and the list of the eleven characteristics of philosophical defensiveness and narcissism. We shall do this later when we turn to look at the reasons for individual differences in epistemological intelligence.

\section{\$7. Non-philosophical studies of so-called "epistemological understanding"}

A second area of research has developed in the past several decades, whose contributors have largely been professors of education and of the psychology of education. Their work has some indirect applicability to an analysis of the skills that constitute epistemological intelligence and deserves brief mention here. These researchers have attempted to relate what they have called "epistemological understanding" to elementary and high school student skills in argumentation. ${ }^{16}$ The notion they employ of "epistemological understanding" is rather general and loosely defined to include four basic aspects of knowing: degree of certainty, simplicity, justification, and source. ${ }^{17}$

Admittedly, their use of the term 'epistemology' has become very casual and semantically undisciplined, and would satisfy few philosophers whose expertise lies in the discipline of epistemology. From the standpoint of technically oriented philosophical

16 Cf., e.g., Weinstock, Neuman, \& Tabak (2004), Mason \& Scirica (2006), Weinstock (2009).

${ }^{17}$ Suggested by Hofer \& Pintrich (1970) and often, with some variations, followed since then, as, for example, by Weinstock (2009). 
epistemologists, the "epistemological understanding" that has interested these authors is situated on a comparatively elementary level, both in terms of the skills involved and the levels of student education that are investigated. Even so, this non-philosophical area of study is one of the few that partially overlaps the interest here in examining the set of skills associated with epistemological intelligence.

The work of these psychologically-focused academicians has tended to endorse a developmental model of cognitive growth, originally proposed by Kuhn (1999, 2000). She suggested that "epistemological understanding" proceeds in a series of stages from childhood to adolescence to adulthood: Childhood absolutism is characterized by the belief that knowledge is definitive, unambiguous, directly based on experience of reality and supported by the imprimatur of authorities. In adolescence, this stage of absolutism gives way to a "multiplist" view that sees knowledge as ambiguous, subjectivist, and relative. And then, by the time adolescents reach early adulthood, they ideally begin to develop a capacity to evaluate knowledge claims critically and to accept the existence of unitary norms of justification and inquiry.

Such an idealized stages-of-development model of the gradual growth of "epistemological understanding" is worth mentioning in our present discussion if only because it parallels on a rudimentary level (of education and of cognitive skills) what we have explicitly in view here. However, although of interest in its own right, a fundamentally questionable aspect of this research is the widely shared belief among many of its researchers that "epistemological understanding" should be considered in "dispositional" terms rather than in terms of an individual's actual competence or general intelligence-meaning that the wide divergence in student performance in tasks that require them to justify basic knowledge claims calls upon their "dispositions" to think in a flexible way and to 
be willing and able to change their beliefs once they encounter contradictory evidence. ${ }^{18}$

To refer to these mental proficiencies (my attempt to use a neutral term) by using the word 'dispositions' is, I think, to suggest that individuals can, at least sometimes, voluntarily change their cognitive behavior provided they are so disposed. I suspect that here the use of the word 'disposition' may bow to political correctness in order to direct attention away from or even to deny individual differences. To my knowledge, however, it has not been shown that the mental proficiencies in question are, as the term 'dispositional' seems to suggest, of a kind that the individual is able, in any sort of comparatively free or unrestricted manner, to change his or her cognitive behavior. These mental proficiencies are, in fact, mental skills that are not equally apportioned or endowed, as I shall try to make clear in what follows. Whether they can be taught or developed through individual initiative may be open to some doubt.

To summarize this and the previous section:

The findings of studies of confirmation bias that relate most directly to the philosophical personality are these: Position-takingof any kind, whether philosophical or not-has a psychological dynamic for which there is now strong evidence. It constitutes a dynamic - that is, an interconnected system-which involves the interplay of the following psychological forces: Once a person takes a position, his or her immediate, virtually automatic psychological tendency is (a) to seek ways to justify it, (b) to perceive reality in conformity with that position, (c) to filter his or her thinking by virtue of the position taken, and (d) to engage in biased evidence

\footnotetext{
18 Stanovich (1999), Stanovich \& West (1997, 1998), Weinstock (2003).
} 
selection, choosing evidence that favors the position, and excluding what does not.

The second area of research that has focused on so-called "epistemological understanding" in students has suggested that as people age, they undergo progressive stages of development in which they, ideally, become increasingly capable of critical thinking in their evaluation of claims to knowledge. To what extent this capacity can be developed through training, to what extent naturally occurring individual differences contribute or interfere, and whether or not individual differences in these proficiencies are "dispositions" or rather "skills" (in the sense of competencies or expressions of intelligence)—all of these pose questions whose answers have not been convincingly established.

Despite important unanswered questions, there are obvious direct applications to the psychology of philosophers of the above findings (a-d) and of the belief that individual proficiencies in evaluating knowledge claims may be developmental, and perhaps also subject to individual differences.

To complete this discussion of confirmation bias in its relation to the psychological profile of philosophers, it will be useful to refer to the list of psychological characteristics given earlier in $\$ 5$. For the reader's convenience in referring to that list, it is reproduced in somewhat abbreviated form on the following page: 
i. Preferred philosophical systems of belief are often rooted in a philosopher's sense of self and professional identity; philosophical disagreement can easily be experienced as personally threatening.

ii. When a system of belief is linked to one's sense of identity, it can close the mind to competing, alternative, or conflicting ideas, and can become a solipsistic ideology, closing off that system of belief from potential challenge.

iii. The result of (i) and (ii) has a filtering effect, which sifts incoming, as well as outgoing, would-be communications with other minds, imposing limits on what one is willing to see, admit, or question.

iv. Philosophical positions, and ideologies generally-like their propounders-become exceptionally resistant to external criticism.

v. A philosopher's system of intellectual and psychological commitments often presumes to be an all-inclusive theory of reality, to "include all relevant evidence," thereby becoming essentially exclusionary.

vi. As a result, philosophical positions, and the philosophers who espouse them, tend to become monadically isolated from one another, blocking genuine communication. vii. As long as (i)-(vi) dominate the psychology of philosophers, genuine controversy and dialogue between competing views cannot succeed.

viii. As a consequence of the foregoing, philosophy, unlike science, has resisted the development of a unitary framework and methodology. Philosophers who have urged the adoption of a shared standpoint and method implicitly advocate abandoning the private willfulness of individual systemsbuilding. (i)-(vi) are compelling psychological forces that stand in the way of doing this.

ix. The psychology of philosophers is characterized by contentiousness, the goal of which is to show that one is right, and that the other is wrong.

x. Philosophical position-taking is essential defensive, seeking to evade criticism, often by means of vagueness, terminological obscurity, and self-insulation from outsiders.

xi. A basic psychological underpinning of philosophy is resistance to external pressures that would force change in positions taken, comprising a kind of "intellectual lassitude" that can mask fear that one's efforts are tenuous or flawed. 
The main findings relating to confirmation bias that have direct application to the philosophical personality are, then, these: Once a person takes a position, his or her immediate, virtually automatic psychological tendency is

(a) to seek ways to justify it,

(b) to perceive reality in conformity with that position,

(c) to filter his or her thinking by virtue of the position taken, and

(d) to engage in biased evidence selection, choosing evidence that favors the position, and excluding what does not.

There are clear-cut correlations between these four propensities and the above combined list of psychological characteristics listed in Table 1.

The drive to find ways to justify a position that one has taken, (a) above, is strongly expressed in the contentious psychological propensity of philosophers to show that one is right and that the other is wrong (ix).

The next two psychologically compelling effects of confirmation bias-to perceive reality, (b), and to filter one's thinking, (c), in conformity with a position that one has taken-take the form in the philosophical personality of filtering incoming, as well as outgoing, would-be communications with other minds; the filter that is established imposes restrictive limits on what one is willing to see, admit, or question (iii).

The last, and most widely recognized effect of confirmation bias, the selection and rejection of evidence to suit the position taken, (d) above, takes the form in the philosophical personality of a selfenclosed, self-isolating, exclusionary system of intellectual and psychological commitments that claim that the philosophical position endorsed includes all relevant evidence (v).

The philosophical characteristics (iii, $\mathrm{v}$, and ix) embody, then, the principal relevant results of studies of confirmation bias. The remaining characteristics (i, ii, iv, vi, viii, $x$, and $x i$ ) complete a 
description of the psychological profile of philosophers that, while sharing several features of the general psychology of confirmation bias found in all position-taking, incorporates a group of further important characteristics.

The single "meta-level" property, that of combining characteristics (i-vi) within a single personality structure (vii), is significant, since it points to the claim implicit in this monograph, that it is by virtue of the combination of the various propensities (i-vi and viii-xi) that a total, integrated psychological profile comes to be. The varied listed psychological characteristics function in synergy: they interact and mutually reinforce one another so as to produce a combined total effect that is psychologically distinctive and of central relevance if philosophy is to achieve its goal of clear and dispassionate self-examination.

The above psychologically-based observations are of potential value to practitioners of philosophy for two principal reasons: they can provide a framework for honest psychological self-examination and growth, and not a depressing dead-end; and they help us to understand important psychological factors that must enter into our understanding of epistemological intelligence, to which subject I now return.

\section{§8. Epistemological intelligence and individual differences}

I know that most men - not only those considered clever, but even those who are very clever, and capable of understanding most difficult scientific, mathematical, or philosophic problems - can very seldom discern even the simplest and most obvious truth if it be such as to oblige them to admit the falsity of conclusions they have formed, perhaps with much difficultyconclusions of which they are proud, which they have taught to others, and on which they have built their lives.

- Leo Tolstoy (1899, p. 124) 
It should by now, I hope, strike most readers that Table 1's set of eleven psychological propensities, when these operate in synergy within the individual philosophizing mind, are essentially undesirable because they are limitative. That is, they stand in the way of an individual's intellectual as well as personal growth, and when they represent the dominant psychological profile of a profession, they similarly stand in the way of its development.

As I have emphasized in previous publications relating to the psychology of philosophers, ${ }^{19}$ observations such as these are not intended, nor should they be taken, as disparaging of the discipline, derogatory, negativist, or an expression of despair. I hold certain of the core objectives of philosophy in high esteem and have sought to make some modest contributions to the discipline that have been motivated by a wish to overcome its undesirable internal limitations. The observations I have attempted to communicate claim to be no more than stepping stones to a psychologically comprehensive understanding of the phenomenon of philosophy, an understanding that may help to advance its development.

In $\$ 2$, I identified a set of Basic Eight skills that I associate with the term 'epistemological intelligence' (again, for the reader's convenience, that list is reproduced here):

(1) a commitment to logical coherence and alertness to inconsistency

(2) a commitment and a sensitivity to identify beliefs that are baseless, that is, have no empirical or logical justification

(3) a commitment and a will to eliminate, to the extent this is individually possible, baseless beliefs from one's own thinking

(4) a commitment to seek revisionary replacements, to the extent that this is conceptually possible, for beliefs recognized as baseless, and a determination to accomplish this

(5) an ability to recognize that all claims to knowledge are inextricably framework-relative, that is, cannot be asserted when disassociated from

19 See note 12. 


the conceptual framework(s) that must be accepted in order for it to be
possible to make those claims
(6) a heightened awareness of the ways in which some scientific and many
commonly accepted and widely used concepts trespass beyond the
frameworks they presuppose, and by doing this, become self-
destructively incoherent
(7) a "mental dynamic" of a certain sort, one that has been developed
within the individual's mind, perhaps through training or perhaps
simply because the person's mind finds this natural, to invest credence
only in rationally justifiable ways of understanding and rationally
justifiable claims that can be made on this basis
(8) the establishment of what I have called a "rational bridge, which
connects the preceding reflectively, self-consciously justified and
formulated understanding and claims, with both the individual's own
predispositions to behave in certain ways, and actual conduct that is
consistent with those predispositions

\section{TABLE 2}

My purpose in this section is to look more closely at these Basic Eight epistemological skills (Table 2) in their relations with both the specific forms of defensiveness exhibited by many philosophers and the defining characteristics of clinical narcissism that apply to the philosophical personality (Table 1). As we shall see, the strength of such relations can facilitate or obstruct the attainment of epistemological skills when these are sought within a psychological framework characterized by these kinds of defensiveness and expressions of narcissism. These relations will explain in large measure the variability that we see in the degree to which individuals can acquire and cultivate those skills.

In a very different context, I described the nature of a "closed system of thought" in the following terms:

A closed system of thought capitalizes on the vicious internal circularity of its method of responding to outside challenges. Thanks to its circular logic, "[t]he 
true believer ... can prove to his satisfaction everything he believes, and he believes everything he can prove" (Koestler, 1967, p. 290). For the believer, his understanding of the world, his emotional approach to it, and the behavior he is motivated to engage in, often to the point of death, all of these are built upon a pathological way of interpreting experience. Experience is, one might say, remapped by the following features: (a) the closed system's immunity to conflicting evidence, that is, its selfinsulating ability to seal itself off from opposition; (b) the unbridgeable separation of human reason and emotion; (c) the closed system's universalizability; (d) irrefutability; and (e) what I have elsewhere ${ }^{20}$ called its self-validating character.... Together, these forces support and maintain a cognitive dynamic that reinforces the species' emotion-dominated response to any form of opposition that questions the needs and interests of the closed system. And many human cognitive frameworks are closed in this way: an ideology, a nation's or a corporation's self-interested policies, a body of religious dogma, any group's selfcentered manifesto, or generally, homocentric selfishness. (Bartlett, 2008, p. 358).

It should be evident that the psychological limitations listed in Table 1 describe a manifestly closed system of thought, one which, if my observations are correct, describes the dominant psychology of philosophers and of many of its students. It should also be evident that this closed system of philosophical thought is, on a fundamental psychological level, incompatible with the essentially open system of thought that is established when all of the skills enumerated in Table 2 are fully functional in an individual mind. Not only are these two sets of propensities incompatible, they are opposed to one another. A mind that possesses the skills listed in Table 2 is "immunized," so to

${ }^{20}$ See note 2 . 
speak, from the self-limiting propensities identified in Table 1. To express this concisely, epistemological intelligence inhibits the formation of characteristic philosophical defenses and philosophical expressions of ideological and intellectual narcissism.

The topic of individual differences has unfortunately, in many applications, become too politically hot for many researchers to handle. We certainly are willing to recognize that at least some human abilities vary widely - that the skills of genius, for example, are not conferred on all equally. Despite the obviousness of this fact, there is a pronounced wish among many researchers today to avoid any reference to cognitive skills that are unequally apportioned in the population. Some of this evasion may be explained because to accept individual differences, especially individual cognitive differences, is to accept some minimal form of "discrimination," even if this minimal form amounts to no more than the ability to discriminate - that is, to perceive and to recognize-more highly developed skills as differentiably distinct from those less developed. The rest of the evasion is explained by a mistaken equation of democratic equality of rights with equality of abilities. From the perspective of any teacher wishing to encourage in his or her students the development of a set of skills, discrimination in the minimal sense mentioned above is essential, for that discrimination is an expression of the sensibility needed to recognize an ideal, an ideal in relation to which the educator's objectives are determined.

This is the case in connection with epistemological intelligence. The set of skills in terms of which it has been defined here are capable of attainment to different degrees by different minds. It is not hard to see why this is the case.

Before proceeding, I want to introduce the reader to what I have called "the Romanes Principle."21 The psychologically-focused observations presented here, made of my philosophical colleagues and students of philosophy over a period of many years, are phenomenologically descriptive and are, at this point, not yet

${ }^{21}$ Bartlett (2011, pp. 203-204). See also Bartlett (2005, pp. 226-227) 
supported by experimental or psychometric studies. This fact does not sit well in the context of the prevailing strong distrust of individual diagnostic judgment when not backed by double-blinded, statistically sound, and replicated experimental studies. In relation to that distrust of individual judgment, the Romanes Principle expresses a viewpoint which today cannot help but appear heretical. However, although there is an important role in science for caution, there is no place in it for thick-headedness. Nineteenth century psychologist George Romanes did not devalue experimental evidence, but he was level-headed:

$[\mathrm{N}]$ o one can have a more lively appreciation than myself of the supreme importance of experimental or historical verification, in all cases where the possibility of such verification is attainable. But in cases where such verification is not attainable, what are we to do? We may either neglect to investigate the subject at all, or we may do our best to investigate it by employing the only means of investigation which are at our disposal.... [1]n the science of psychology, nearly all the considerable advances which have been made, have been made, not by experiment, but by observing mental phenomena and reasoning from these phenomena deductively. (Romanes, 1895, p.12)

Once reasoning based on observation does provide a demonstration of a certain fact, we will sometimes find that "the proof itself is too complete to admit of any question.” (Romanes, 1889, p. 400)

There are, Romanes suggested, facts we can come to know about the world, and specifically about psychology, that do not rest on or require experimental verification. In the case of philosophy's psychological underpinnings, I will go out on a non-experimental limb, affirm the Romanes Principle, and claim that we do not need to cringle in a state of dependency upon as yet unperformed 
psychological experiments that would verify what the history of philosophy already confirms. There is a place for phenomenological description that does not require experimental, statistical buttressing.

Once a basis has been established in phenomenological description, there is also a place for plausible reasoning. I now call on the reader to accompany me in taking a few plausible steps:

There are psychologically simple reasons why people find the skills I have associated with epistemological intelligence to be challenging, and, furthermore, often emotionally and intellectually inapplicable to their outlooks and unacceptable to their persons. Table 1 expresses certain of these reasons, reasons that especially affect philosophers. What we are faced with are psychological facts, borne out by the discipline's long history and by the psychological profile of the majority of philosophers and students who are attracted to philosophical study. They are psychological facts-also strongly supported by evidence from clinical psychology, psychiatry, ethology, and quantitative history-about the normal buman psychological constitution at this time in our species' development. ${ }^{22}$

We may sum up what most plausibly happens when, to use a mechanical analogy, a thinker's mental "gears" - consisting of the philosophical forms of defensiveness and narcissism (Table 1)-are engaged in pursuit of the ideal goal defined by the skills fundamental to epistemological intelligence (Table 2): The gears will grind, will refuse to mesh, and will resist forward motion. The psychologically normal mind experiences deeply rooted recalcitrance when faced with the challenge, or with the need, to revise or let go of beliefs that are emotionally or intellectually gratifying. The internally interconnected psychological system of the philosophizing mind, whose dynamic inherits and ties together the functioning of the psychologically normal mind's operation, is governed by the interplay of the set of forces of defensiveness and narcissism, forces which themselves resist the formation and cultivation of epistemological skills.

${ }^{22}$ For a detailed study in support of this statement, see Bartlett (2011, esp. Chap. 9 and Appendix III, “The Distribution of Mental Health”), and Bartlett (2005). 
Specifically, again referring to Table 2 , the psychologically normal human mind experiences great reluctance to give up baseless, unjustified beliefs (3); it summons negligible determination to seek revisionary replacements for such baseless beliefs (4); and it balks at the injunction not to trespass beyond presupposed frameworks of reference (6), for that injunction is mightily resisted by the psychologically normal mind that is accustomed to, and yearns for, "projective" 23 access to supposed truths and corresponding realities that transcend the very possibility of access to them. At the same time, comparatively few individuals possess a conceptual make-up that limits their beliefs to rationally justifiable understanding and rationally justifiable claims (7), and, in my own observations, even fewer people possess minds in which a "rational bridge" exists to connect reflective, rational understanding and claims with actual cognitive and behavioral conduct consistent with their rationality (8).

When the skills I have associated with epistemological intelligence are sought, the mind encumbered by the limitations identified in Table 1 experiences the unavoidable consequences of these limitative psychological and cognitive deficiencies. To use a mechanical analogy again, the accelerator is pressed with the brakes fully engaged.

On the positive side, the skills associated with logical coherence (1), a capacity to become aware of baseless beliefs (2), and the ability to recognize the framework-relativity of claims (5) are skills whose formation and development the normal human mind resists less: It is not uncommon for psychologically normal individuals to be able to develop these abilities. But "resisting less" does not by any means entail that the corresponding motivational components will be present. The skill of being alert to inconsistency (1), the commitment to identify baseless beliefs (2), and the determination to exercise the ability to recognize framework-relativity (5), these all involve active volition and resolve, and here the normal human mind's intellectual lassitude or lethargy (Table 1, xi) tends to play a dominant role.

${ }^{23}$ See $\int 4$ and the Appendix to this monograph. 


\section{\$9. Can epistemological intelligence be taught? Can it be learned?}

The first goal in studying any specific variety of intelligence is to understand the set of skills that make it possible. Once that understanding is attained, how to implement that understanding to make the skills associated with that form of intelligence more accessible and more achievable for people is a more distant goal. But the understanding must come first.

In \$3 I referred to my study of the variety of intelligence that I have called "moral intelligence." Related to this work, a number of researchers have examined what they believe are distinguishable developmental levels of "moral reasoning," ${ }^{24}$ much like levels of "epistemological understanding" are described by educators and psychologists of education. In the case of moral reasoning, there is unfortunately scant evidence (in fact I know of none) to show that the level of an individual's moral reasoning is reflected in his or her actual moral behavior in real life. To be "morally intelligent" requires the existence of a "moral bridge" that connects moral reasoning with actual behavior consistent with that reasoning; such a bridge is a comparative rarity in the psychologically normal population. ${ }^{25}$

A parallel issue concerns the unreliable to non-existent "rational bridge" in many people (Table 2, (8)). There is no question that many individuals can, through effective training, improve their reasoning skills. Not only this, but there is some evidence that some of the skills associated with general intelligence can be improved through teaching that specifically focuses on the development of problemsolving skills. ${ }^{26}$ There is again, however, as in the case of moral

\footnotetext{
${ }^{24}$ For references to the literature, see Bartlett (2005, Chap. 18 and passim).

25 See note 22.

26 This area of investigation remains controversial. To cite evidence here only from the author's own research: With grant funding from the Lilly Endowment, at Saint Louis University during the years 1976-83, I designed and regularly offered a campus-wide course, Patterns of Problem Solving, that provided students with training in a wide range of problem-solving skills. Pre- and post-testing of students
} 
reasoning skills, a paucity of evidence to show that general reasoning skills carry over to an individual's subsequent rational thinking and behavior. Here, too, a "bridge" between developed intellectual skills and later cognitive and behavioral conduct is, at best, shaky.

The two "bridges" I have described would ideally link, in the one case, moral reasoning to moral behavior, and in the other, reasoning skills to subsequent rational thought and behavior.

What is needed is an "affective cement" that welds moral perception and reasoning to behavior. Conviction, as commonly understood, serves this connective function; it acts as the bridge that unifies an individual's judgment, reasoning, and beliefs with behavior that conforms to them. Without conviction, reasoning falls on deaf ears; without conviction, there is no need for moral or reflective judgment to be expressed through behavior in real life. Seen in this way, conviction is a genuine ability, an ability to connect strongly felt emotions with behavior consonant with them. It is what enables someone who is persuaded by reflective thought or by moral principle to act consistently with that thought or principle. (Bartlett, 2005, p. 280)

This manner of speaking is evidently impressionistic; it makes recourse to analogy and metaphor, and is imprecise clearly because of a lack of empirical data in this area. Notwithstanding the Romanes Principle, my commentary here is forced to be objectionably general. -Of course there are no such "bridges," though perhaps neuroanatomists may in time discover neural structures or patterns of

enrolled in this class showed significant improvements in IQ as measured by the California Test of Mental Maturity (see Bartlett (1976-77)). Students whose IQs were measured could not, however, be followed longitudinally in later years to determine whether their IQ gains were long-lasting or short-lived. 
organization in the human brain that provide these figures of speech with a physiological basis. ${ }^{27}$

Although stated informally and figuratively, the point here, however, will, I hope, not be lost on the reader - that the set of epistemological skills I have identified require just the kind of "cement" that joins together rationality with conviction. ${ }^{28}$ In the description of the epistemological skills enumerated in Table 2, the term 'commitment' plays a central role in the description of the first four skills; the seventh skill emphasizes the need for a "mental dynamic," that is, the establishment of an abiding and ongoing way of thinking that invests credence only in what is rationally based. These are the psychological equivalents of the "cement" alluded to in the passage quoted above.

Although certain of the skills associated with general intelligence may be teachable, and although to some extent some individual students can "be motivated" by their teachers, the kind of strongly internalized mental and psychological commitments to which epistemological intelligence refers are not at present known to be teachable. Perhaps some students can respond to efforts of their teachers who strive to teach epistemological thinking, and can successfully acquire the mental dynamic I am referring to, but generally, at least in my own teaching experience, this is a rarity.

This seems to me much like the fact that only a minority of students of the violin, for example, are able to become highly skilled musicians, while others who may practice just as hard, never can. In music, it is not an intellectual embarrassment to refer to "talent," an inborn, native capacity to excel as a musician. To say that a high degree of skill reflects "talent" is an admission that we don't know where it comes from or how to bring it about.

\footnotetext{
${ }^{27}$ Even if and when this happens, the two "bridge problems" are merely shifted to a different level: With neurological region locating information in hand, merely by virtue of it we will still not know how to bring about such bridges in individuals who do not have them.

${ }^{28}$ Cf. Bartlett (1969-70).
} 
We are much less inclined to accept that in an academic discipline like epistemology anything resembling "talent" should be involved; we much prefer to believe that any dedicated student with a collegelevel amount of general intelligence should be able to become a competent epistemological thinker. At least in connection with the skills I have described, in my experience, this is far from being the case. But more importantly, the strong incompatibilities that exist between Table 2's skills and Table 1's psychological limitations lead to the same conclusion.

If epistemological intelligence cannot in any reliable sense be taught, can it then be learned? That is, can the relevant skills be learned by an individual whose reasoning capabilities are good and who is, moreover, strongly self-motivated? In this case, from what I have observed, the answer is that sometimes, yes, he or she can. But when this happens it is not as though the professor of epistemology has transferred by means of effective communication and training exercises the skills that the "receptive" student is then able to cultivate, internalize, and make the scaffolding of his or her mental operations. In a very real sense, for such a student, the professor is "preaching to the already convinced"-in other words, to the "epistemologically talented."

At one point in the Divine Comedy, when Dante meets St. Thomas Aquinas in Paradise, St. Thomas cautions him: "opinion-hastyoften can incline to the wrong side, and then affection for one's own opinion binds, confines the mind." ${ }^{29}$ - Already in Dante's 13th century, the closed system of much human thinking was evident.

The skills of epistemological intelligence are some of them specialized, and some very general, but taking them together as a

${ }^{29}$ Mandelbaum \& Moser (1980, Paraiso, canto XIII, 118-120). 
group, they make it possible, in the technical philosophical framework of epistemology, for the skilled mind to "think outside the box," to cut the shackles that hold thought bound to accustomed beliefs that provide gratification, security, and reinforcement of the self. And yet such skills are able to do this in a way that exercises the thinker's mental restraint in recognizing the limitations of the frames of reference required for knowledge claims to be possible, and by doing this, to avoid transgressing their boundaries. There are some boxes outside of which it is profitable to think, and others outside of which lies only incoherence. 


\section{APPENDIX}

Readers unfamiliar with the author's concept of projection and with de-projective methodology may find the following short example useful:

\section{The Projection of Transcendence ${ }^{30}$}

The tendency has always been strong to believe that whatever receives a name must be an entity of being, having an independent existence of its own. And if no real entity answering to the name could be found, men did not for that reason suppose that none existed, but imagined that it was something peculiarly abstruse and mysterious.

- John Stuart Mill, quoted in Spearman (1927, p. 14)

The human belief in transcendence is a disorder of thought: It involves a peculiar variety of conceptual error, a projective misconstruction beyond whatever reference frame is in use, plus the predication of independent existence to what is projected. This belief is common among people in all societies. It takes many forms: the child's belief that a tree must make a crashing sound when there is no one there to hear it; belief in deities who live in a heavenly dimension to which living human beings have no access; belief that a nation possesses a supervening identity and reality for which it makes sense to sacrifice life; the belief that is typical of so many ideologies — that they define an autonomous reality in which the sole, exclusionary, and unique Truth is to be found; and of course the metaphysician's belief in the reality of objects "in themselves." When these beliefs are

${ }^{30}$ Portions of this Appendix are taken from the author's book, The Pathology of Man (2005, pp. 303-304). 
carefully analyzed, none is found to have meaning, for the meaning they are thought to have-and the meaning they can be thought to have-is dependent upon and inextricably linked to the reference frames that are used to think and articulate those beliefs.

Epistemological contentions like these, however, can be intellectually slippery, for neither do the opposite claims make sense: It is equally meaningless to claim that the unobserved falling tree does not make a sound. - To assert this is not to espouse positivism or operationalism, but rather to endorse a framework-relative criterion of meaning, ${ }^{31}$ which is no more than to recognize that the very identity of objects to which we refer is a framework-relative matter. It is to claim no more than that the point defined by the coordinates $(3,-5,5)$ has no identity if we are prevented from using a three-dimensional Cartesian coordinate system.

From this point of view, transcendence is a concept, to paraphrase Clifton Fadiman, that looks in vain for a meaning on the scrap heap of popular misuse. We have become so inured to claims that involve its use, and so comforted by the psychological and existential reassurance that it appears to offer, that we cannot see that we hold beliefs in something that is not false, but absurd-that is, incoherent, meaningless. When we make claims that involve the notion of transcendence, we trespass beyond the boundaries of meaningful reference; we step out of bounds, forget where we are, and believe that we have thought a thought that makes good sense, or said something meaningful. In fact, we have not. ${ }^{32}$

For a reflective, epistemologically intelligent person to believe in transcendence is intellectual hypocrisy. Epistemological intelligence fuses conviction and rationality in insisting upon a meaningful understanding of reality, one which is, that is to say, "de-projectively" coherent. Intelligence of this kind is able to free itself from projective misconstructions, of which transcendence is unfortunately but one among many of the epistemologically delusional beliefs that distort

\footnotetext{
31 Bartlett (1982).
}

32 Bartlett (1982). 
the human comprehension of reality. Other conceptually pathological beliefs relate to commonly held notions about the identity of others and of oneself, material objects, time and space, truth, causality, theism, atheism, agnosticism, etc. ${ }^{33}$

33 For further explanation and justification, see, e.g., Bartlett (1970, 1976, 1983a, 2005, 2011, 2015, 2016). 


\section{REFERENCES}

Bartlett, Steven James (1969-70). Conviction and rationality. A paper presented at the Center for the Study of Democratic Institutions, Santa Barbara, CA. Available online from PhilPapers: https://philpapers.org/rec/BARCAR-6

Bartlett, Steven James (1970). A relativistic theory of phenomenological constitution: A self-referential, transcendental approach to conceptual pathology. Vol. I: French; Vol. II: English. Ph.D. dissertation, Université de Paris. University Microfilms Intl. \#7905583. Available online from: http://repub.eur.nl/res/pub/41645/ and https://philpapers.org/rec/BARART-7

Bartlett, Steven James (1975). Metalogic of reference: A study in the foundations of possibility. Starnberg, Germany: Max- Planck-Gesellschaft.

Bartlett, Steven James (1976). The idea of a metalogic of reference. Methodology \& Science 9:3, pp. 85-92. Available online from: https://philpapers.org/rec/JAMTIO-7

Bartlett, Steven James (1976-77). Patterns of problem-solving: A final report of work undertaken with the support of the Lilly Endowment. Saint Louis, MO: Saint Louis University. Available online from: http://www.willamette.edu/ sbartlet/Documents/Bartlett_Patterns $\%$ 20of $\% 20$ Problem-solving $\% 20-\% 20$ Report.pdf.

Bartlett, Steven James (1980). Self-reference, phenomenology, and philosophy of science. Methodology and Science: Interdisciplinary Journal for the Empirical Study of the Foundations of Science and Their Methodology, 13:3, pp. 143-167. Available online from: https://philpapers.org/rec/BARSPA-20.

Bartlett, Steven James (1982). Referential consistency as a criterion of meaning. Synthese, 52, pp. 267-82. Available online from: https://philpapers.org/rec/BARRCA.

Bartlett, Steven James (1983a). Conceptual therapy: An introduction to frameworkrelative epistemology. St. Louis, MO: Studies in Theory \& Behavior. Available online from: http://repub.eur.nl/pub/78880

Bartlett, Steven James (1983b). Philosophy as conceptual therapy. Educational Resources Information Center, Natl. Inst. of Ed., Dept. of Health, Ed., \& Welfare: May. Document \#ED 224402. 
Bartlett, Steven James (1986a). Philosophy as ideology. Metaphilosophy, 17:1, pp. 1-13. Available online from: https://philpapers.org/rec/BARPAI.

Bartlett, Steven James (1986b). Narcissism and philosophy. Methodology and Science: Interdisciplinary Journal for the Empirical Study of the Foundations of Science and Their Methodology, 19:1, pp. 16-26. Available online from: https://philpapers.org/rec/JAMNAP

Bartlett, Steven James (1989). Psychological underpinnings of philosophy. Metaphilosophy, 20:3 \& 4, pp. 295-305. Available online from: https://philpapers.org/rec/STEPUO.

Bartlett, Steven James (2002). Roots of human resistance to animal rights: psychological and conceptual blocks." Animal Law, 8, pp. 143-76. Available online from: https://www.animallaw.info/sites/default/files/lralvol8 p143.pdf

Bartlett, Steven James (2005). The pathology of man: A study of human evil. Springfield, IL: Charles C. Thomas.

Bartlett, Steven James (2008). The humanistic psychology of human evil: Ernest Becker and Arthur Koestler. Journal of Humanistic Psychology, 48:3, pp. 340-363. DOI: $10.1177 / 0022167807305249$

Bartlett, Steven James (2011). Normality does not equal mental health: The need to look elsewhere for standards of good psychological health. Santa Barbara, CA: Praeger.

Bartlett, Steven James (2015). The species problem: Inescapable ambiguity and redundancy. Monograph available from:

ArXiv.org: http://arxiv.org/abs/1510.01589

CogPrints: http://cogprints.org/9956/

HAL: https://hal.archives-ouvertes.fr/hal-01196519)

PhilSci: http://philsci-archive.pitt.edu/11655/.

Bartlett, Steven James (2016). Paratheism: A proof that God neither exists nor does not exist. Published online; available from:

http://philpapers.org/rec/BARPAP-20

Binet, Alfred \& Henri, Victor (1895). La psychologie individuelle. L'Année psychologique, 2, pp. 411-465.

Bruner, J. S. Tagiuri, R. (1954). The perception of people. In Lindzey, G. (ed.), Handbook of social psycbology, pp. 634-54. Reading, MA: AddisonWesley. 
Gardner, Howard (1993). Multiple intelligences: The theory in practice. New York: BasicBooks.

Gardner, Howard (1993/1983). Frames of mind: The theory of multiple intelligences. New York: BasicBooks. First pub. 1983.

Goleman, Daniel (1995). Emotional intelligence. New York: Bantam.

Guilford, J.P. (1967). The nature of buman intelligence. New York: McGrawHill.

Hofer, B. K., \& Pintrich, P. R. (1997). The development of epistemological theories: Beliefs about knowledge and knowing and their relation to learning. Review of Educational Research, 67, pp. 88-140.

Husserl, Edmund (1965). Philosophy as rigorous science. Quentin Lauer (trans.). In Phenomenology and the crisis of philosophy. New York: Harper and Row.

Koestler, Arthur (1967). The ghost in the machine. New York: Macmillan.

Kuhn, D. (1999). A developmental model of critical thinking. Educational Researcher, 28, pp. 16-26.

Kuhn, D. (2000). Theory of mind, metacognition, and reasoning: A lifespan perspective. In P. Mitchell, \& K. J. Riggs (Eds.), Children's reasoning and the mind, pp. 301-326. Hove, UK: Psychology Press.

Kunda, Z. (1990). The case for motivated reasoning. Psychological Bulletin, 108, pp. 480-498.

Mandelbaum, Allen \& Moser, Barry (1980). The Divine Comedy of Dante Alighieri. Berkeley, CA: Univ. of California Press.

Mason, Lucia \& Scirica, Fabio (2006). Prediction of students' argumentation skills about controversial topics by epistemological understanding. Learning and Instruction, 16, pp. 492-509.

Nickerson, Raymond S. (1998). Confirmation bias: A ubiquitous phenomenon in many guises. Review of General Psychology, 2:2, pp. 175220.

Passmore, John (1961). Philosophical reasoning. London: Gerald Duckworth.

Romanes, George John (1888). Mental evolution in man: Origin of buman faculty. New York: Appleton.

Romanes, George John (1895). Mental evolution in animals. New York: Appleton. 
Salovey, Peter \& Mayer, John D. (1990). Emotional intelligence. Imagination, Cognition, and Personality, 9:3, pp. 185-211.

Spearman, Charles E. (1927). The abilities of man. New York: Macmillan.

Stanovich, K. E. (1999). Who is rational? Studies in individual differences in reasoning. Mahwah, NJ: Lawrence Erlbaum Associates.

Stanovich, K. E., \& West, R. F. (1997). Reasoning independently of prior belief and individual differences in actively open-minded thinking. Journal of Educational Psychology, 89, pp. 342-357.

Stanovich, K. E., \& West, R. F. (1998). Individual differences in rational thought. Journal of Experimental Psychology: General, 127, pp. 161-188.

Thorndike, E.L. (1920). Intelligence and its uses. Harper's Magazine, 140, pp. 227-235.

Tolstoy, Leo [Tolstoi, Lyof N.] (1899). What is art? Aylmer Maude (trans.). New York: Thomas Y. Crowell \& Co.

Watanabe, S. (1985). Pattern recognition: Human and mechanical. New York: Wiley.

Watanabe, Satosi (1965). Une explication mathématique du classement d'objets. In S. Dockx and P. Bernays (Eds.), Information and prediction in science: Proceedings of a symposium sponsored by the Académie Internationale de Philosophie des Sciences, Brussels 3-8, September, 1962, pp. 39-76. New York: Academic Press.

Watanabe, Satosi (1969). Knowing and guessing: A quantitative study of inference and information. New York: John Wiley.

Watanabe, Satosi (1986). Epistemological relativity. Annals of the Japan Association for Philosophy of Science, 7:1, pp. 1-14.

Weinstock, M., \& Cronin, M. A. (2003). The everyday production of knowledge: Individual differences in epistemological understanding and juror-reasoning skill. Applied Cognitive Psychology, 17, pp. 161-181.

Weinstock, Michael (2009). Relative expertise in an everyday reasoning task: Epistemic understanding, problem representation, and reasoning competence. Learning and Individual Differences, 19:4, pp. 423-434.

Weinstock, Michael; Neuman, Yair; \& Tabak, Iris (2004). Missing the point or missing the norms? Epistemological norms as predictors of students' ability to identify fallacious arguments. Contemporary Educational Psychology. 29:1, pp. 77-94. 


\section{About THE Author}

Homepage: http://www.willamette.edu/ sbartlet

Steven James Bartlett was born in Mexico City and educated in Mexico, the United States, and France. He did his undergraduate work at the University of Santa Clara and at Raymond College, an Oxford-style honors college of the University of the Pacific. He received his master's degree from the University of California, Santa Barbara; his doctorate from the Universite de Paris, where his research was directed by Paul Ricoeur; and has done post-doctoral study in psychology and psychotherapy at Saint Louis University and Washington University. He has been the recipient of many honors, awards, grants, scholarships, and fellowships. His research has been supported under contract or grant by the Alliance Française, the American Association for the Advancement of Science, the Center for the Study of Democratic Institutions, the Lilly Endowment, the Max-PlanckGesellschaft, the National Science Foundation, the Rand Corporation, and others.

Bartlett brings to the present work a background in epistemology and clinical psychology. He is the author or editor of more than 20 books and monographs, and many papers and research studies in the fields of psychology, epistemology, mathematical logic, and philosophy of science. He has taught at Saint Louis University and the University of Florida, and has held research positions at the Max-Planck-Institut in Starnberg, Germany and at the Center for the Study of Democratic Institutions in Santa Barbara. He has received honorary faculty research appointments from Willamette University and Oregon State University, and now devotes full-time to research and publication. 